\title{
Agreement in the assessment of practical skills in basic CPR between observers and a CPR mannequin with a specific software
}

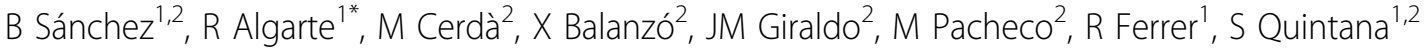 \\ From ESICM LIVES 2015 \\ Berlin, Germany. 3-7 October 2015
}

\begin{abstract}
Introduction
Conducting a training activity usually involves assessing to students the knowledge and/or the skills acquired. Assessment methods must be objectives and representatives of the item being evaluated and able to ensure their independence from the evaluator. The assessment of practical skills in cardiopulmonary resuscitation (CPR) acquired by a student during a training course conforming the quality criteria for CPR on adults (2010 International Guidelines on Resuscitation ${ }^{1}$ ), continues to be accomplished currently by observers. Increasingly, other objective methods of assessment (CPR manikin with specific ${ }^{2}$ software, mechanical devices, etc.) of these skills with an excellent degree of accuracy and feedback, are being extended. The correct evaluation of these practical skills is crucial to ensure their correct acquisition, as a first step to the translation into clinical practice.
\end{abstract}

\section{Objectives}

To check the agreement between three different observers to each other and with a mechanical device with a specific software for CPR.

\section{Methods}

Descriptive and univariate analysis according to Cohen's Kappa coefficient and the intraclass correlation coefficient (ICC). 54 volunteers, health workers, with training and experience in CPR, performed a complete sequence of basic CPR maneuvers in a dummy (Laerdal PC v 4.2.1 Skill Reporting Software) (L). Three expert instructors (A, B and $\mathrm{C}$ ) in teaching courses in CPR evaluated,

${ }^{1}$ Hospital Universitario Mutua de Terrassa, Intensive Care Department,

Terrassa, Spain

Full list of author information is available at the end of the article visually, the performing of correct external chest compressions regarding the placement of the hands, depth compression and decompression, and rate. We analyze the concordance between the observers (A, B and C) among themselves and with $\mathrm{L}$.

\section{Results}

Table 1 shows the mean scores of A, B, C and L for the 54 students. Table 2 shows the crude concordance, the value of Cohen's kappa coefficient and the ICC. Figure 1 shows the Bland and Altmann graphics. We can observe that the degree of agreement and uniformity among the 4 evaluators are poor, and there is a high degree of dispersion without a defined trend.

\section{Conclusions}

The CPR skills assessment in a visual way by expert evaluators is associated with an important lack of agreement and a high dispersion. At present, it must pose routinely the use of mechanical devices for training and evaluation of these skills.

\section{Authors' details \\ ${ }^{1}$ Hospital Universitario Mutua de Terrassa, Intensive Care Department, Terrassa, Spain. ${ }^{2}$ Consell Català de Resuscitació, Barcelona, Spain.}

Published: 1 October 2015

Table 1 Mean scores

\begin{tabular}{lll}
\hline EVALUATORS & MEAN & SD \\
\hline$A$ & 51.8 & 26.8 \\
\hline$B$ & 62.8 & 27.6 \\
\hline$C$ & 65.7 & 20.3 \\
\hline$L$ & 55.1 & 20.7 \\
\hline
\end{tabular}


Table 2 Concordance between pairs of evaluators

\begin{tabular}{llll}
\hline EVALUATORS & Crude concordance $\%$ & Cohen's Kappa $(\mathbf{K})$ coefficient & Intraclass correlation coefficient \\
\hline A-B & 78 & 0.52 & 0.54 \\
\hline A-C & 74 & 0.45 & 0.45 \\
\hline B_C & 85 & 0.70 & 0.43 \\
\hline A-L & 74 & 0.45 & 0.53 \\
\hline$B-L$ & 66 & 0.35 & 0.56 \\
\hline$C-L$ & 70 & 0.41 & 0.44
\end{tabular}

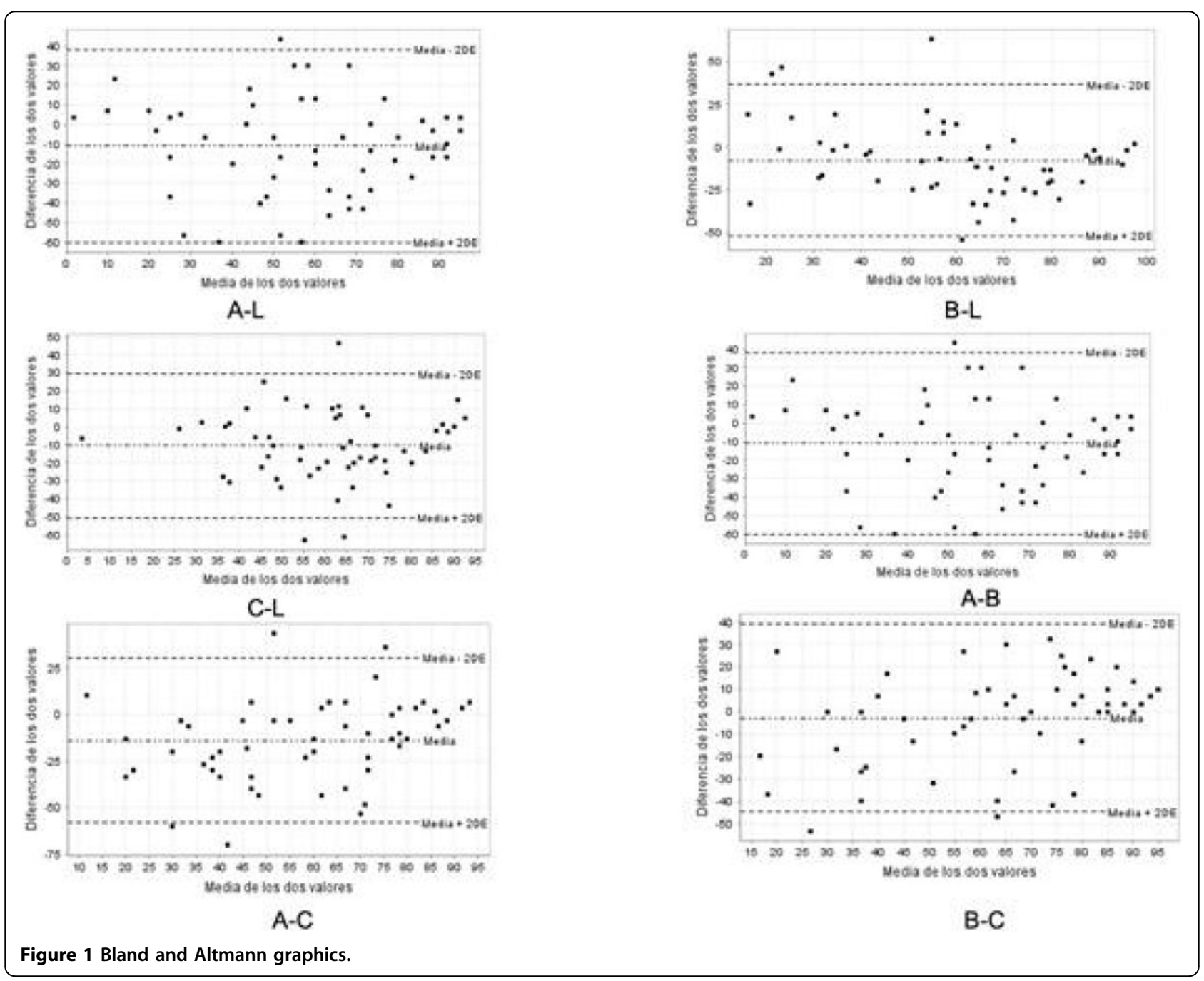

\section{References}

1. Michael R Sayre, Rudolph W Koster, Martin Botha, Diana M. Cave, Michael T. Cudnik, Anthony J. Handley, Tetsuo Hatanaka, Mary Fran Hazinski, lan Jacobs, Koen Monsieurs, Peter T. Morley, Jerry P. Nolan, Andrew H. Travers: Part 5: Adult Basic Life Support 2010 International Consensus on Cardiopulmonary Resuscitation and Emergency Cardiovascular Care Science WithTreatment Recommendations. Circulation 2010, 122(S298):S324.

2. Zhang FL, Yan L, Huang SF, Bai XJ: Correlations between quality indexes of chest compression. World J Emerg Med 2013, 4:54-8.
doi:10.1186/2197-425X-3-S1-A749

Cite this article as: Sánchez et al: Agreement in the assessment of practical skills in basic CPR between observers and a CPR mannequin with a specific software. Intensive Care Medicine Experimental 2015 3(Suppl 1):A749. 